2

\title{
Delayed haemorrhage following pelvic side wall excision with internal iliac vessel resection in locally recurrent rectal cancer
}

Short Title: Haemorrhage post iliac resection in LRRC

Authors:

Jordan M Hamilton MBBS, MTrauma

Tomas J Larach MD, SChCP

Alexander G Heriot MB, BChir, MA, MD, MBA, FRACS, FRCS(Gen.), FRCSEd, FACS, GAICD

Satish K Warrier MBBS, MS, FRACS

Jacob J McCormick MBBS, FRACS

Institution: Division of Cancer Surgery, Peter MacCallum Cancer Centre, Victorian Comprehensive Cancer Centre, Melbourne, Victoria, Australia.

Declaration: There are no conflicts of interest to declare and no funding was required for this project. The corresponding author is not the recipient of any research scholarships, this manuscript is not based on any previous communication or publication.

Word count: 743

Number of figures: 3

Corresponding Author:

Jordan M Hamilton

Email: jordan.m.hamilton@gmail.com

Postal address: 9 Amelia Street, Brunswick Victoria, 3056.

Phone: +61421315697

En-bloc iliac resection as a component of pelvic exenteration for locally recurrent rectal

cancer (LRRC) can be associated with major morbidity including major haemorrhage. While

This is the author manuscript accepted for publication and has undergone full peer review but has not been through the copyediting, typesetting, pagination and proofreading process, which may lead to differences between this version and the Version of Record. Please cite this article as doi: $10.1111 /$ ans.15734

This article is protected by copyright. All rights reserved. 
thankfully rare, major haemorrhage in this setting carries a risk of death and requires prompt and sometimes novel techniques for timely management.

An 81-year-old male presented with recurrence of a node positive rectal cancer treated 17 years prior with ultralow anterior resection and adjuvant chemoradiation. The recurrence was diagnosed on positron emission tomography (PET) scan to investigate new right sided ureteric obstruction. The patient underwent a normal pre-operative colonoscopy and the eventual histopathology confirmed the recurrent nature of the rectal adenocarcinoma. Preoperative PET and magnetic resonance imaging (MRI) indicated a metabolically active soft tissue mass in the right pelvic sidewall which involved the right distal ureter as well as the right internal iliac vessels.

After multidisciplinary discussion, the patient underwent long course chemoradiotherapy of 39.6 Grey in 22 fractions with concurrent oral capecitabine. Reirradiation of this nature for LRRC has been associated with excellent symptom response rates and increased median survival when combined with radical surgery ${ }^{1,2,3}$. Restaging PET and MRI scans demonstrated partial metabolic response in the right pelvic mass.

Preoperative functional evaluation confirmed an eastern cooperative oncology group (eCOG) status of 0 and an Australian modified Karnofsky performance scale (AKPS) score of 90. After completing a five-week exercise and conditioning program, the patient underwent 
a laparotomy with re-do ultralow anterior resection and en-bloc resection of the right ureter, right internal iliac artery and vein, S2/3 nerve roots and piriformis muscle with intraoperative radiotherapy and side to end coloanal anastomosis. The right ureter was reimplanted with a Boari flap and a diverting loop ileostomy was created. Intraoperatively, right uretereolysis and division was performed at the level of the pelvic brim and the plane of dissection continued into the pelvis lateral to the right internal iliac vessels. The vessels were divided and their pedicles secured with hem-o-lok clips in addition to being suture ligated with 2-0 prolene (Figure 1). Despite the previous radiotherapy and the previous pelvic surgery, the operation was uncomplicated and excellent haemostasis was achieved.

The patient's post-operative course was complicated by a urine leak from the Boari flap reimplantation which was diagnosed thirteen days post-operatively on intravenous pyelogram (Figure 2). This required insertion of a right sided nephrostomy tube. The patient made a good recovery and was subsequently discharged to a rehabilitation facility after 27 days.

While in rehabilitation, on the $41^{\text {st }}$ post-operative day, the patient was diagnosed with a right sided, above-knee deep vein thrombosis and was commenced on therapeutic enoxaparin. The patient developed new-onset pain with coldness of the right leg on the $50^{\text {th }}$ post-operative day, which was not reported to the treating team.

This article is protected by copyright. All rights reserved. 
On the $52^{\text {nd }}$ post-operative day, the patient developed high volume per rectal bleeding and was transferred to an acute emergency department in haemorrhagic shock. A CT aortogram showed active haemorrhage from a pseudoaneursym originating from the right internal iliac artery pedicle which was closely associated with a pelvic collection. In addition to a massive transfusion, the patient required emergency coil angioembolisation of the right internal iliac pedicle, intensive care admission and subsequent occlusion of the right internal iliac artery stump with a covering stent three days later (Figure 3). The patient had a second episode of low volume PR bleeding on the $67^{\text {th }}$ post-operative day and returned to theatre for angioembolisation of a bleeding inferior gluteal vessel. His recovery was otherwise uncomplicated.

The most important prognostic factor for LRRC is achieving clear margins of surgical resection (RO). It is recognised that RO resection rates are lower in LRRCs that involve the lateral pelvic compartment ${ }^{4,5}$, however these rates have improved from $19-21.5 \%$ to as high as $66.5 \%$ in high-volume centres over the last 20 years ${ }^{6,7}$. This is partly due to en-bloc resection techniques of the iliac vessels, ureter, pelvic side wall musculature and sacral nerve roots where required. A large case series from a high volume institution reported their rates of post-operative morbidity following exenteration with lateral compartment pelvic dissection which included pelvic collection at $13 \%$, urological leaks following diversion at $14 \%$ and major haemorrhage at $3 \%^{6}$. These figures are improved from a previous case series by the same authors that quoted major haemorrhage rates at $8 \%^{8}$. In the case

This article is protected by copyright. All rights reserved. 
described above, the presence of a large pelvic collection originating from a urinary leak was identified as a potential contributor to the delayed haemorrhage.

Awareness of the potential risk of secondary haemorrhage following pelvic sidewall vessel resection is important. Development of advanced interventional radiology techniques, combined with heightened awareness of the potential complications and symptoms, are important tools required to manage this life-threatening complication.

\section{$\underline{\text { References }}$}

1. Ng MK, Leong $T$, Heriot AG, Ngan SY. Once-daily reirradiation for rectal cancer in patients who have received previous pelvic radiotherapy. J Med Imaging Radiat Oncol. 2013; 57: 512-518.

2. Bosman SJ, Holman FA, Neiuwenhuijzen GA, Martijn H, Creemers GJ, Rutten HJ. Feasibility of reirradiation in the treatment of locally recurrent rectal cancer. $\mathrm{Br} \mathrm{J}$ Surg. 2014; 101: 1280-1289.

3. Heriot AG. Commentary: Feasibility of reirradiation in the treatment of locally recurrent rectal cancer (Br J Surg 2014; 101: 1280-1289). Br J Surg. 2014; 101: 1289

4. Bird TG, Ngan SY, Chu J, Kroon R, Lynch AC, Heriot AG. Outcomes and prognostic factors of multimodality treatment for locally recurrent rectal cancer with curative intent. Int. J. Colorectal Dis. 2018; 33: 393-401.

This article is protected by copyright. All rights reserved. 
5. Moore HG, Shoup M, Riedel E et al. Colorectal cancer pelvic recurrences: determinants of resectability. Dis. Colon Rectum. 2004; 47: 599-606.

6. Solomon MJ, Brown KGM, Koh CE, Lee P, Austin KKS, Masya L. Lateral pelvic compartment excision during pelvic exenteration. Br. J. Surg. 2015; 102: 1710-1717.

7. Lee, DJK, Sagar PM, Sadadcharam, G, Tan KY. Advances in surgical management for locally recurrent rectal cancer: How far have we come? World J. Gastroenterol. 2017; 23: 4170-4180.

8. Austin KK, Solomon MJ. Pelvic exenteration with iliac vessel resection for lateral pelvic wall involvement. Dis. Colon Rectum. 2009; 52: 1223-1233.

This article is protected by copyright. All rights reserved. 


\section{Figure Legends}

Figure 1. Intraoperative photograph of dissected right pelvic sidewall showing divided internal iliac artery and vein pedicles (white arrow).

Figure 2. Computed tomography intravenous pyelogram showing right sided urinoma (red arrow) abutting right common iliac vessels.

This article is protected by copyright. All rights reserved. 
Figure 3. (a) Angiogram of right iliac vessels showing internal iliac artery pedicle with pseudoaneurysm (blue arrow) and active haemorrhage (red arrow). (b) Post-intervention angiogram of right iliac vessels showing coil angioembolisation of right internal iliac artery and covering stent. CIA: Common iliac artery, EIA: External iliac artery.

This article is protected by copyright. All rights reserved. 


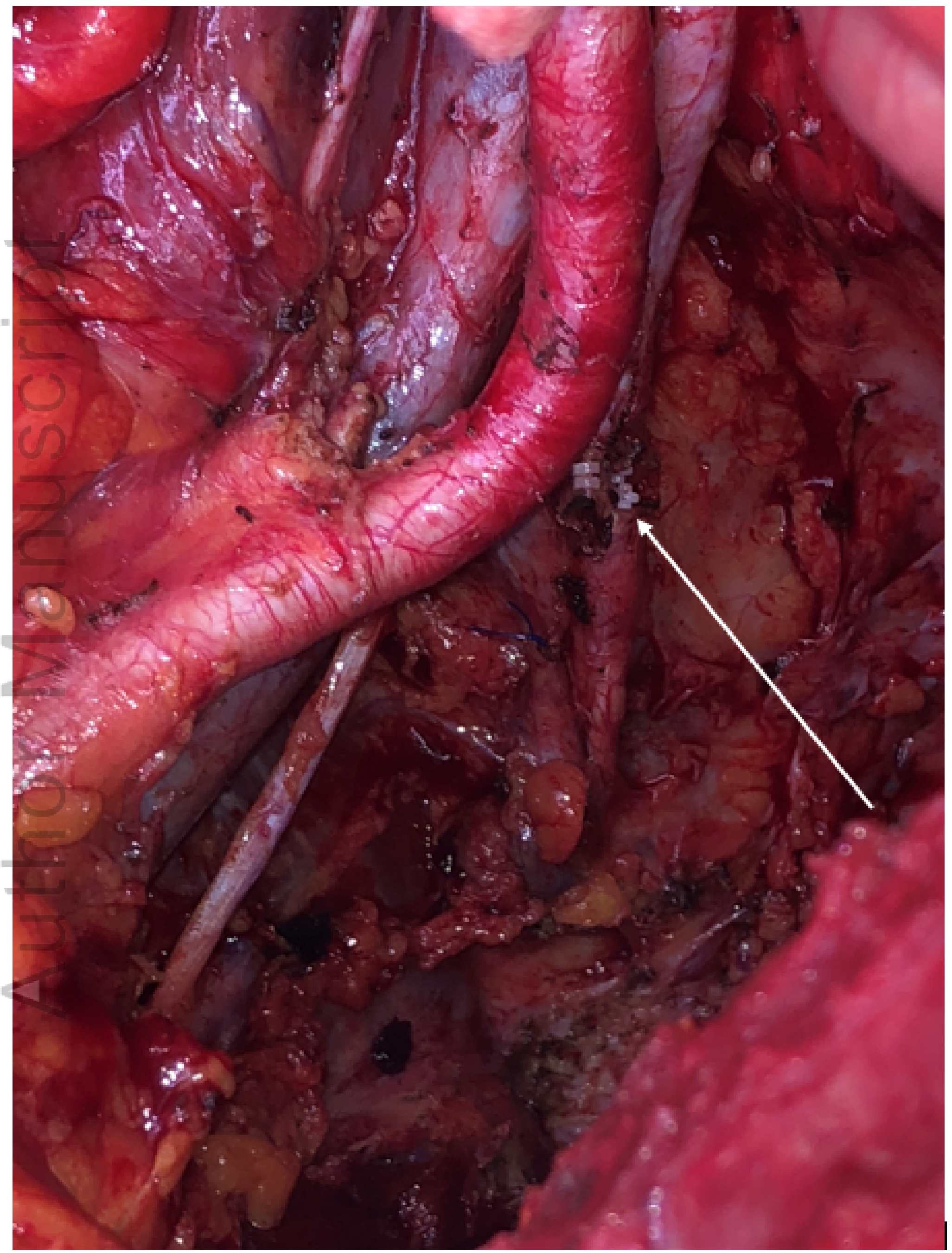




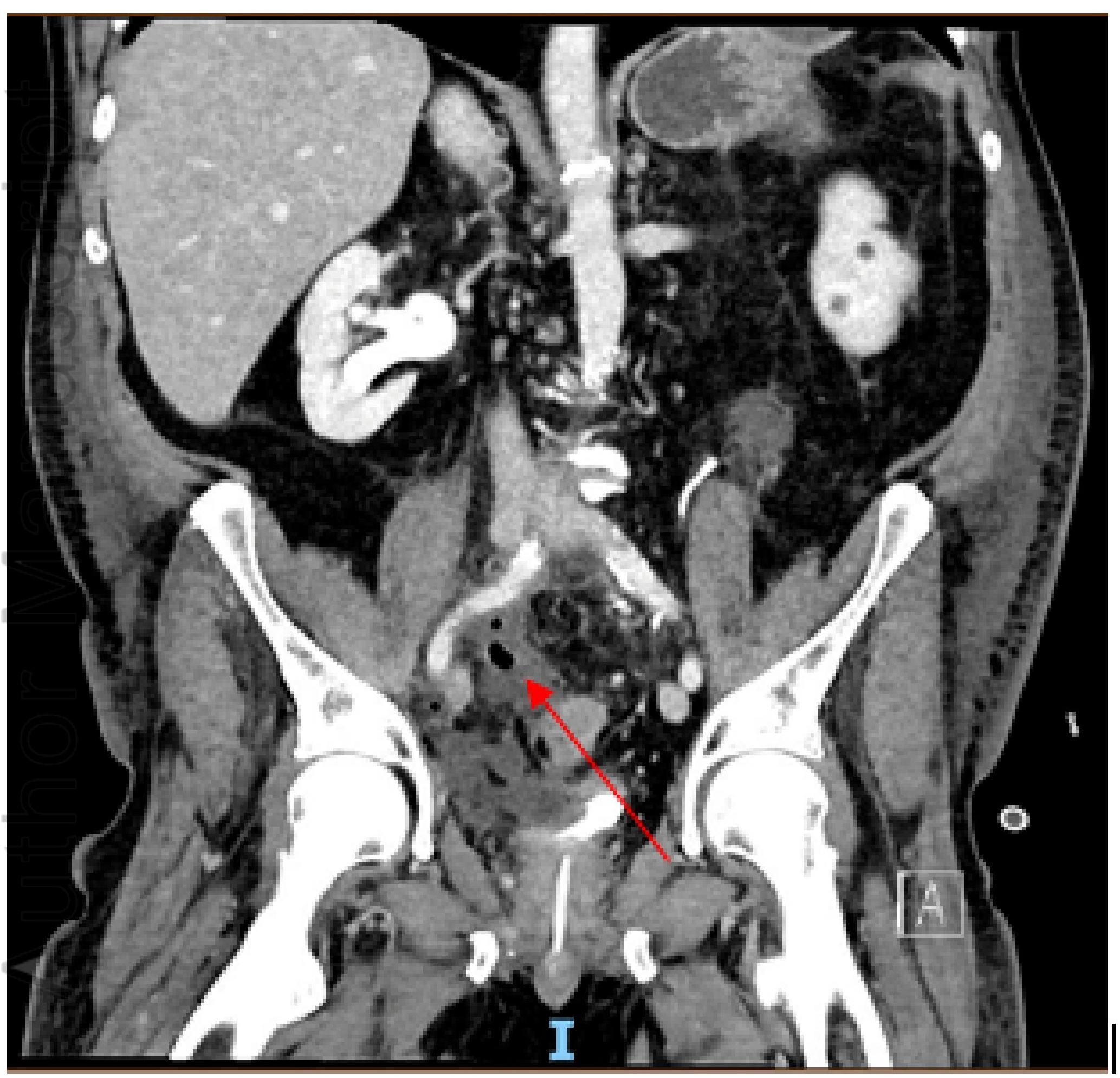

ANS_15734_Figure 2. Urinoma.PNG 


\section{University Library}

\section{- M I N E R VA A gateway to Melbourne's research publications}

Minerva Access is the Institutional Repository of The University of Melbourne

Author/s:

Hamilton, JM;Larach, TJ;Heriot, AG;Warrier, SK;McCormick, JJ

Title:

Delayed haemorrhage following pelvic side wall excision with internal iliac vessel resection in locally recurrent rectal cancer

Date:

2020-01-28

Citation:

Hamilton, J. M., Larach, T. J., Heriot, A. G., Warrier, S. K. \& McCormick, J. J. (2020). Delayed haemorrhage following pelvic side wall excision with internal iliac vessel resection in locally recurrent rectal cancer. ANZ JOURNAL OF SURGERY, 90 (10), pp.2125-2127. https:// doi.org/10.1111/ans.15734.

Persistent Link:

http://hdl.handle.net/11343/275311 